\title{
QUEEN'S
UNIVERSITY
BELFAST
}

\section{A qualitative exploration of proxy decision makers' expectations of prescribed medications for people with advanced dementia}

McCloskey, B., Hughes, C., \& Parsons, C. (2018). A qualitative exploration of proxy decision makers' expectations of prescribed medications for people with advanced dementia. Palliative Medicine, 32(6), 11141123. https://doi.org/10.1177/0269216318757163

Published in:

Palliative Medicine

Document Version:

Peer reviewed version

Queen's University Belfast - Research Portal:

Link to publication record in Queen's University Belfast Research Portal

Publisher rights

(C) 2018 the Authors.

This work is made available online in accordance with the publisher's policies. Please refer to any applicable terms of use of the publisher.

\section{General rights}

Copyright for the publications made accessible via the Queen's University Belfast Research Portal is retained by the author(s) and / or other copyright owners and it is a condition of accessing these publications that users recognise and abide by the legal requirements associated with these rights.

Take down policy

The Research Portal is Queen's institutional repository that provides access to Queen's research output. Every effort has been made to ensure that content in the Research Portal does not infringe any person's rights, or applicable UK laws. If you discover content in the Research Portal that you believe breaches copyright or violates any law, please contact openaccess@qub.ac.uk. 
1 A qualitative exploration of proxy decision makers' expectations of prescribed

2

3

4

5

6

7

8

9

10

11

12

13

14

15

16

17

18

medications for people with advanced dementia

\section{Expectations of medications in advanced dementia}

Bridgeen McCloskey PhD, MPharm, MPSNI. Altnagelvin Area Hospital, Glenshane Road, Londonderry, BT47 6SB, United Kingdom. Email: bmccloskey05@qub.ac.uk

Carmel Hughes, PhD, BSc, MPSNI. School of Pharmacy, 97 Lisburn Road, Belfast, Queen's University Belfast, BT9 7BL, United Kingdom. Email: c.hughes@qub.ac.uk; Telephone: +44 (0) 289097 2147; Fax: +44 (0) 2890247794.

*Carole Parsons PhD, MPharm, MPSNI. School of Pharmacy, 97 Lisburn Road, Belfast, Queen's University Belfast, BT9 7BL, United Kingdom. Email: c.parsons@qub.ac.uk; Telephone: +44 (0) 289097 2304; Fax: +44 (0) 289024 7794. *Corresponding author

\section{What is already known about this topic?}

- Patients with advanced dementia often cannot participate in decision-making about their care; proxy decision-makers (family members, friends or next of kin) therefore make decisions on their behalf

- Proxy decision-makers' expectations of medications have the potential to influence decisions to prescribe or withdraw medications

- The few studies conducted to date which explore proxy decision-makers' expectations of medications for patients with dementia consider all stages of disease and do not focus on the advanced stages of the condition

\section{What this paper adds?}

- This study is the first to explore and describe proxy decision-makers' expectations of prescribed medications for people with advanced dementia, and to consider how these expectations may change with changing goals of care and disease progression 
- Proxy decision-makers felt that they had a key role in acting as an advocate and providing information to health care professionals for the person for whom they made decisions, particularly about any symptoms experienced. They reported an expectation for more information about prescribed medicines, and specifically wanted details such as indications, benefits and risks of treatment. Although some expected to be involved in medication-related decisions, the majority preferred to delegate these decisions to healthcare professionals. However, they expected to be informed of any medication-related decisions made

- Despite uncertainty about the benefits of anti-dementia medications, proxy decisionmakers were reluctant for these medications to be withdrawn. Reluctance to stop other prescribed medicines was also expressed, due to fear of potential consequences. However, this reluctance reduced as proxy decision-makers considered changing goals of care and dementia progression

\section{Implications for practice, theory or policy?}

- Communication between healthcare professionals and proxy decision-makers regarding prescribed medications (indications, risks, benefits) is of critical importance

- Proxy decision-makers vary in terms of their desire for active involvement in the medication decision-making process. Healthcare professionals should facilitate proxy decision-maker involvement if desired

- Healthcare professionals must elicit and manage proxy decision-makers' expectations for prescribing medications in advanced dementia and must inform proxy decision-makers of all prescribing decisions made

\section{Abstract}

Background: Proxy decision-makers often have to make decisions for people with advanced dementia. Their expectations regarding prescribed medications have the potential to influence prescription or withdrawal of medications. However, few studies to date have explored this. Aim: To explore proxy decision-makers' expectations of prescribed medications for people with advanced dementia, and to consider how these change with changing goals of care and dementia progression. Design: Qualitative semi-structured 
interview study. Setting/participants: Fifteen proxy decision-makers of people with advanced dementia were recruited via general practitioners $(n=9)$, Join Dementia Research (JDR) $(n=3)$, and the Alzheimer's Society Northern Ireland $(n=3)$. Results: Five key themes emerged: the role as advocate; attitudes to medicines and medicine taking; uncertainty over the benefit of anti-dementia medications; stopping medications; and communication and decision-making. Proxy decision-makers desired more information about prescribed medicines, particularly the indications, benefits and risks of treatment. Despite uncertainty about the benefits of anti-dementia medications, proxy decision-makers were reluctant for these medications to be withdrawn. Reluctance to stop other prescribed medicines was also expressed, but reduced with changing goals of care and dementia progression. Although some proxy decision-makers expected to be involved in medication-related decisions, the majority preferred to delegate these decisions to healthcare professionals. However, they expected to be informed of any medication-related decisions made. Conclusions: Proxy decision-makers vary in terms of their desire for active involvement in the medication decision-making process. Healthcare professionals should facilitate proxy decision-maker involvement if desired. Further research is required to consider the impact of proxy decision-maker involvement in decision-making.

\section{Keywords: Dementia, Decision making, Older people, Medication, Prescribing}

\section{Introduction}

Dementia is a progressive, chronic, incurable neurodegenerative condition in which widespread neuronal cell death results in multiple deficits across cognitive domains including: memory, behaviour, language, movement and executive function, and ability to recognise familiar people or common objects. ${ }^{1,2}$ Disease progression is characterised by cognitive and physical decline which can adversely impact on ability to conduct basic and instrumental activities of daily living, ${ }^{3-5}$ accompanied by an increasing dependence on others for care. ${ }^{6-8}$ Stage 7 of the Functional Assessment Staging Test (FAST) (ranging from 7A to 7F, with $7 \mathrm{~F}$ indicating the most severe dementia) provides a useful description of the features of advanced dementia including profound memory deficits, minimal verbal abilities, inability to ambulate independently, inability to perform any activities of daily living, urinary and faecal incontinence, inability to sit up without assistance and loss of the ability to smile in the very 
late stages. ${ }^{9}$ Patients with advanced dementia often cannot participate in decision-making about their care. ${ }^{10}$ Consequently, decisions are made by proxy decision-makers: family members, friends and next of kin who act in their best interest. ${ }^{11-15}$

People with dementia and their caregivers hold high expectations for new medications, ${ }^{16}$ which may be unrealistic, leading to disappointment and dissatisfaction with care. ${ }^{17}$ Managing the expectations of proxy decision-makers is an important aspect of treatment in advanced dementia, ${ }^{18}$ as they have the potential to influence the prescription or withdrawal of medications in this vulnerable patient group. ${ }^{19-23}$ However, despite the importance of expectations in shaping the decision-making process, ${ }^{24-26}$ few studies have explored proxy decision-makers' expectations of medications in advanced dementia; studies considering all stages of disease have reported that anti-dementia medicines (acetylcholinesterase inhibitors [AChEIs] including donepezil, galantamine and rivastigmine, which inhibit breakdown of acetylcholine, an important neurotransmitter for memory) gave people hope, ${ }^{20,27-29}$ and despite lack of clarity about their benefits, were "worth a try", ${ }^{30}$ with fears about deterioration if these medications were stopped. ${ }^{27}$ This study aimed to contribute to the limited evidence base.

\section{Aim}

To explore proxy decision-makers' expectations of prescribed medications for people with advanced dementia. The following objectives were identified:

- To investigate what information is provided to proxy decision-makers about prescribed medications for people with advanced dementia

- To explore proxy decision-makers' expectations regarding prescribed medications for the person with advanced dementia

- To explore proxy decision-makers' experiences of and/or views on decision-making regarding medication use and how these change as dementia progresses

- To consider how proxy decision-makers would feel about the withdrawal of prescribed medications if goals of care changed due to dementia progression

\section{Methods}


Setting/participants

126 Proxy decision-makers of people with advanced dementia in a region of the UK (Northern 127 Ireland [NI]) were recruited. A proxy decision-maker was defined as: an adult family 128 member or friend in regular contact (on at least one occasion per week) with the person 129 with advanced dementia, who was their next of kin, or made decisions about the care of 130 that person in conjunction with healthcare professionals. Further inclusion criteria were as 131 follows:

- FAST score of between 7A and 7F for the patient's cognitive function, indicating severe/advanced dementia. ${ }^{9}$ Proxy decision-makers completed this instrument as a proxy measure of function.

- Superficial knowledge of medication(s) prescribed (names and broad purpose)

Sampling and recruitment

Purposive sampling was undertaken to identify proxy decision-makers of people with advanced dementia. Recruitment was undertaken by mail, telephone or face-to-face via general practitioners, Join Dementia Research (JDR), and the Alzheimer's Society, NI. The researcher $(\mathrm{BMCC})$ only contacted individuals who had returned completed contact consent forms to indicate interest in participation.

Ethical approval

NHS Research Ethics Committee approval was obtained in February 2016 (West of Scotland Research Ethics Service [WoSRES]; reference 16/WS/0029).

\section{Study design and data collection}

150 Face-to-face, semi-structured interviews were conducted by BMcC (a postgraduate researcher and qualified pharmacist) in proxy decision-makers' homes using an interview schedule (Table 1) to facilitate sensitive, flexible, in-depth exploration of individuals' views within an overarching structure by which commonalities of experience could be identified. ${ }^{31}$ Interview questions were developed following literature review and discussions within the research team, and refined based on feedback from piloting. No prior relationships existed 
between participants and the researcher before study commencement. Participants were aware that the researcher was a postgraduate student from the School of Pharmacy, Queen's University Belfast. Participants provided written informed consent. Recruitment continued until analysis revealed no further novel themes emerging.

\section{Data analysis and validation}

Data collection was undertaken between March 2016 and May 2016. Interviews were digitally audio-recorded and transcribed verbatim. Transcripts were anonymized using a unique code comprising "PDM" (proxy decision-maker) and a number to reflect the sequence in which participants were interviewed.

Interviews were conducted and analysed by a female pharmacist of Irish descent (BMcC), who had undertaken training in qualitative research methods. Data analysis was iterative, with simultaneous data collection and analysis leading to alterations in the interview schedule in line with emerging themes. ${ }^{32}$ The framework method of analysis developed by Ritchie and Spencer ${ }^{33}$ was applied to the data generated. Microsoft Word was used to aid with data management. Validation of analysis was performed ( $\mathrm{CP}, \mathrm{BMcC})$ and consensus reached on the final themes.

\section{Results}

Twenty of 35 proxy decision-makers (57.1\%) approached expressed interest in the study. Fifteen $(42.9 \%)$ met the inclusion criteria and agreed to take part; of these nine were recruited via GPs, three via JDR and three via the Alzheimer's Society, NI. Interviews lasted an average of 37.5 minutes (range: 24-60 minutes). Demographic characteristics of participants are detailed in Table 2.

Five key themes emerged from the interviews: (1) the role of the proxy decision-maker as advocate, (2) attitudes to medicines and medicine taking, (3) uncertainty over the benefit of anti-dementia medicines, (4) stopping medications and (5) communication and decisionmaking.

\section{The role of the proxy decision-maker as advocate}


Proxy decision-makers reported that they knew the person with advanced dementia better than anyone else, including healthcare professionals. As a result, they felt they had a critical role in interpreting their symptoms. were keen for medications to be reviewed.

Proxy decision-makers expected medications to be prescribed for control and/or relief of symptoms and comfort, particularly towards the end of life. They advocated for prescription of medications in some instances, and in other cases, requested withdrawal.

"I feel that the doctor would have a better idea about [my husband's] symptoms, if he asked me about them. I mean I am with him all the time whereas the doctor only sees him briefly when we have problems, realistically how can he make good conclusions about his symptoms without asking me?" PDM10

\begin{abstract}
"As she approaches the end of life she would need to get the medications that make her comfortable, that is really important for me...mummy doesn't have a voice, she has dementia, I am her voice, so it is my responsibility that she gets all the medicines that she needs." PDM3
\end{abstract}

He is a diabetic as well...and they started him on a drug called metformin but he got severe diarrhoea with that and I requested that it be stopped. I mean I would rather him have slightly high blood sugar levels rather than diarrhoea because diarrhoea is much more upsetting for him and me also... in the future as he approaches the end of life, I don't think he will really need the tablet now because he won't be able to eat as much..." PDM10

Proxy decision-makers placed hope in certain medications and as a result expected to see improvements in their loved one's condition. However, the side-effects of some medications e.g. antipsychotics, mitigated against this hopefulness. In such cases, proxy decision-makers
"I expected that this drug [risperidone] would make things better for her, you know, that she wouldn't be as scared but I was disappointed and scared myself as it left her so drowsy and out of it. I mean I couldn't even enjoy my visit to the nursing home to 
see her as it just made me so upset. Even the word risperidone makes me feel scared. I asked the doctor to review the tablet due to the symptoms [my sister] was experiencing." PDM9

\title{
Attitudes to medicines and medicines taking
}

Proxy decision-makers highlighted the difficulties associated with trying to administer medications.

"Getting them [medicines] down is the problem...the one in the morning goes into the porridge but it has to be crushed...but she doesn't eat all of the porridge, so I have no way of knowing how much of the medication [my sister] is actually taking, and that could be so dangerous for her..." PDM12

When swallowing became problematic proxy decision-makers expected a medication review to determine if the number of medicines could be reduced and to ensure that all medications were prescribed with a clear and current rationale.

\begin{abstract}
"[My wife] has to take ten different tablets each morning and night...it is a constant struggle for me and a real worry because she has such a poor swallow...it has been a while since her tablets have been reviewed and I think now that her swallow is so bad, now would be a good time to do it again...I would be relieved if she had to take less medicines." PDM13
\end{abstract}

Proxy decision-makers required more information about the person's prescribed medications, emphasising the importance of having an appreciation of how medications work and what to expect in relation to benefits and adverse effects. Some held the belief that it was their responsibility to seek such information.

"No one gives me any information about the tablets, that is for me to do myself on the Internet." PDM1 
256 Others expected details to be provided by the prescribing physician, GP or pharmacist.

257 However, in some cases it was apparent that this information was not provided.

258

259

260

261

262

263

264

265

266

267

268

269

270

271

272

273

274

275

276

277

278

279

280

281

282

283

"I expect the doctor [GP] maybe to tell me that level of detail [how the medications work] and to be honest they don't always provide it...if you had a pharmacist to tell you in a common sense kind of way, the important points about medications..." PDM11

Proxy decision-makers also discussed specific medications and drug classes. Cardiovascular medications, including $\beta$-adrenoreceptor blocking drugs, anticoagulants, statins and angiotensin-converting enzyme inhibitors, were considered essential; proxy decision-makers believed these would prevent major cardiovascular events such as myocardial infarction and stroke.

"The statin she needs because her cholesterol is so high, my expectation of it is that it will prevent further heart attacks and strokes from happening, so it is really important that she takes this tablet." PDM3

\section{Uncertainty over the benefit of anti-dementia medicines}

Proxy decision-makers appeared uncertain over the benefits of AChEls and memantine, with many reporting no perceived advantages.

"They [doctors] told me a load of nonsense. That this drug [memantine] would help her dementia, that it would slow the process down...... I don't think it is helping her at all." PDM2

"I would have to say that I don't think [my dad] is getting any benefit from donepezil...I therefore suppose that I don't really expect much in the line of that drug if I am been honest." PDM7

Others were unsure about the effect of these medications because they had no way of telling what their loved one would be like if they were not taking it. 
"The consultant told me that memantine would slow the dementia down...it is difficult to say whether it has slowed it down or not because I can't tell what the dementia would be like if he wasn't taking it, you know." PDM5

\section{Stopping medicines}

Opinions varied regarding stopping anti-dementia medications and other prescribed medications, as detailed below.

\section{Anti-dementia medications}

Some proxy decision-makers were reluctant for these medications to be stopped due to concerns that this could cause deterioration in their loved one's condition.

"I wouldn't want to stop them [donepezil and memantine] because I would be afraid of what would happen if she stopped them, so we are just happy for her to continue to take them until whatever time she passes." PDM11

Interestingly, others felt that such medications were making their loved one's condition worse, and conveyed a sense of relief when these medications were stopped.

"I was quite happy to get her off them [donepezil and memantine], because she is well advanced in her Alzheimer's and I don't see any sense in her being comatosed more [sic], because I do think the tablets comatosed [sic] her. To calm her down I think they really made her more dysfunctional rather than anything else." PDM9

\section{Other prescribed medications}

While some proxy decision-makers felt that a review was necessary to reduce the number of prescribed medications, others were reluctant for medications to be stopped, citing concerns over potential consequences. However, as their loved one's condition began to deteriorate, many felt that some medications no longer had a role to play.

"If you took it away [temazepam] I don't know if it would make an awful lot of difference given how much she sleeps anyway, I mean she basically sleeps for the 
same amount of time as she is awake during the day now. Essentially I think it is just, I think it is part of coming to the end of life and closing down." PDM11

"We wouldn't protest, if anything, with [my wife], she is not going to get better, I know she is going to get worse. Sometimes I do think that the donepezil is there just because she has dementia, I mean her dementia is so advanced now I wonder is there even any point in her taking it at this stage?" PDM14

\section{Communication and decision-making}

Some proxy decision-makers explained that they found making medication-related decisions extremely difficult.

\section{"I find it so difficult to make decisions for [my sister] because I know absolutely} nothing about the brain...it is different if you break a leg or you break an arm and somebody says will we give her a painkiller, certainly yes, but I don't know what is going on in anybody's mind...because she can't tell me...lt is awful hard [sic] making decisions for what tablets people should have for their mind...I hate it. I have to say, I really do." PDM9

Decisions were guided by what proxy decision-makers believed the person with advanced dementia would have wanted.

"I suppose I would think back on the life [we] had together and I know the type of person he is, so I would base my decisions on what I think [he] would decide for himself." PDM10

Proxy decision-makers expected any changes in medications to be communicated to them, particularly when medications were stopped.

"I expect more in the way of communication from healthcare professionals... I mean I expect to be told when there are any changes to my mum's medicines...I believe the reasoning behind why they would be taking her off drugs to be very important to me..." PDM3 
The majority felt that healthcare professionals were equipped with the knowledge and expertise about medications to enable appropriate treatment decisions. Many felt that they did not possess the knowledge to make such decisions themselves. Some explained how they trusted their healthcare professional to make prescribing decisions, and they did not see it as their right to challenge those decisions.

However, despite this trust, proxy decision-makers wished to be kept informed of the decisions made about their loved one's medications. Conversely, some proxy decisionmakers desired greater involvement and a more active role in the decision-making process.

\section{Discussion}

Main findings of the study

Proxy decision-makers felt it was their role to advocate for the person with advanced dementia. They expected healthcare professionals to ask about symptoms, prescribe medications to treat those symptoms, and ensure comfort. The care of people with dementia towards the end of life is often less than optimal, ${ }^{34-38}$ and there is a need for highquality palliative care for patients with dementia, with palliation of symptoms leading to improved comfort and quality of life. ${ }^{39-43}$ 
Proxy decision-makers in the current study expected prescribed medications to be reviewed as swallowing difficulties manifested and dementia progressed, as reported by others. ${ }^{44}$ Similar to the present study, the taking of medications in advanced illness has previously been described as a 'daily struggle' by some caregivers. ${ }^{45}$

Proxy decision-makers viewed cardiovascular medicines as essential to prevent major cardiovascular events. However, studies which have examined medication appropriateness in dementia using expert consensus panels have categorised $\beta$-adrenoreceptor blocking drugs as "sometimes appropriate" and statins as "never appropriate" in advanced dementia, ${ }^{46,47}$ anticoagulants as "rarely appropriate" 46 or "never appropriate" 47 , and ACE inhibitors as "sometimes appropriate" 46 or "never appropriate". ${ }^{47}$ The recently developed Medication Appropriateness Tool for Co-morbid Health conditions in Dementia (MATCH-D) criteria also suggest that antihypertensive agents, lipid-lowering medications, and antiplatelet, anti-coagulant and anti-thrombotic agents should be ceased in late-stage dementia. ${ }^{48}$ Despite these recommendations, patients with advanced dementia often continue to receive medications of questionable benefit. ${ }^{49-52}$ Proxy decision-makers' opinions of these medications may help to explain why they continue to be prescribed in advanced disease.

Many proxy decision-makers in the current study felt they lacked information or access to a reliable source of information about medications prescribed for the person with advanced dementia. Some thought it was their responsibility to actively seek such information, and accessed the Internet to search for details pertaining to prescribed medications. Healthcare professionals should acknowledge the Internet as an information source about prescribed medications, be prepared to offer suggestions for appropriate Internet health resources and assist in evaluating the quality of the information obtained. medications because they had no way of measuring their effects, a finding also reported by others. ${ }^{53}$ Despite this, there was reluctance for these medications to be stopped due to fear that withdrawal could accelerate disease progression or lead to the reintroduction of anxiety, aggression, and challenging behaviours. A qualitative study focusing on AChEls 
426 considered the views of caregivers of people with mild-to-advanced dementia. ${ }^{27}$ Similar to

427 the present study, carers expected that withdrawal would hasten disease progression.

428 Other studies have suggested that discontinuation of anti-dementia medications may 429 worsen the chronic disease, particularly in those who initially respond to treatment, ${ }^{54-57}$ and 430 there have been reports of abrupt decline in cognitive or functional abilities in patients or 431 emerging challenging behaviours upon discontinuation. Conversely, others suggest that 432 AChEl discontinuation is safe and well tolerated in the majority of institutionalized 433 patients. ${ }^{58}$ Further studies are required to evaluate the effects of anti-dementia medication 434 discontinuation, adding to the limited evidence base for patients with advanced dementia.

Proxy decision-makers in this study expressed reluctance over stopping other prescribed medications, which reduced as the condition of their loved one deteriorated, and as end of life approached. This reflects previous work which reported that caregivers could foresee a time when the symptoms associated with memory loss or with another illness might become so severe that taking a medication to treat memory loss was no longer desirable. ${ }^{59}$

Similar to the study by Caron et al., ${ }^{60}$ proxy decision-makers expected changes to medications to be communicated to them. Medication management has been defined as one of many domains of care provided by caregivers ${ }^{61}$ and includes roles such as: administering multiple medications; avoiding medication errors and possible drug interactions; looking for side-effects; making judgements regarding when to withhold, increase, decrease or discontinue a medication; and trying to make informed decisions about their medication management role by communication with healthcare providers. ${ }^{62,63}$ These roles are often made more difficult by unhelpful structures and practices in different 450 healthcare settings. For example, changes to prescribed medications may not be communicated to caregivers if they were not present during the consultation. ${ }^{64}$ The

452 importance of improving communication between healthcare professionals and caregivers 453 in end of life care settings and for those dying with dementia has been acknowledged. ${ }^{65,66}$ 454 Recent work has identified the potential application of the MATCH-D criteria as a discussion 455 aid or educational tool to facilitate this communication. ${ }^{67}$ The revised Patients' Attitudes 456 towards Deprescribing (rPATD) questionnaire also shows promise as a tool to supplement 
and guide communication about stopping medications and to highlight proxy decisionmaker beliefs and attitudes towards deprescribing. ${ }^{68}$

460 Caregivers find decisions around end of life care very difficult. In situations where the wishes of the patient are not known in advance, they are helped by knowing the views held by the person with dementia before losing capacity. ${ }^{13}$ Communication between proxy decisionmakers and healthcare professionals is vital to explore and understand the patient's previously stated goals and values, which should then guide and facilitate treatment decisions. Dementia-specific advance directives, which address change in cognition and goals of care as dementia progresses and are completed by patients before dementia occurs, would provide proxy decision-makers with even greater reassurance that the treatment they choose is guided by what the patient would have wanted. ${ }^{69}$

Proxy decision-makers varied in their need to be actively involved in medication-related decisions. The majority were happy to delegate to, and placed substantial trust in, healthcare professionals; they did not feel that they had the appropriate medical knowledge to make such decisions, a finding reported by others. ${ }^{60}$ The integral role of the physician in this regard has emerged in previous studies. ${ }^{23,43,60,70}$ In all cases, being informed of decisions made was essential for reassurance about the care received, and to meet the expectation concerned with the proxy decision-maker's own sense of involvement in such care.

\section{Limitations of the study}

479 Limitations must be acknowledged and considered when interpreting the data. This study 480 recruited a sample from a very specific population of proxy decision-makers for people with advanced dementia in one region of the UK (NI); as a result, there is the potential for sampling bias. $^{71}$ Selection bias may be present as proxy decision-makers with no understanding of their loved one's medications were not recruited. One approach suggested to address this problem is through the generation of a larger sample size. ${ }^{72}$ However, as this study reached data saturation, this was not considered necessary. ${ }^{32,71}$ 
In the present study, proxy decision-makers of people with advanced dementia advocated

489

490

491

492

493

494

495

496

497

498

499

500

501

502

503

504

505

506

507

508

509

510

511

512

513

514

515

516

517

518

519

520 for medicines to be prescribed to ensure their loved one's comfort, especially towards the end of life. Future research should explore the extent to which proxy decision-makers' expectations are met in relation to ensuring comfort as end of life approaches, and their role in the decision-making process regarding initiation, continuation or withdrawal of medications. Further understanding of and insight into communication between healthcare professionals and proxy decision-makers and the complexity of the healthcare professionalproxy decision-maker relationship are critical in the development of an intervention or bestpractice model that will serve to facilitate decision-making processes for people with advanced dementia.

\section{What this study adds}

This study is the first to explore proxy decision-makers' expectations of prescribed medications in advanced dementia, and to consider how these may change with changing goals of care and disease progression. Communication between healthcare professionals and proxy decision-makers regarding prescribed medications is of critical importance. Healthcare professionals should facilitate proxy decision-maker involvement in the medication decision-making process if desired.

\section{Conclusion}

Proxy decision-makers described their role as advocate and providing information to healthcare professionals, particularly about symptoms experienced. They reported an expectation for more information about prescribed medicines, specifically regarding indications, benefits and risks of treatment. Proxy decision-makers expressed reluctance at stopping prescribed medicines due to fear of potential consequences. However, this appeared to reduce with changing goals of care and dementia progression. Although some expected to be involved in medication-related decisions, the majority preferred to delegate these decisions to healthcare professionals. However, they expected to be informed of any decisions made. Further work is required to identify the impact of proxy decision-makers' expectations for prescribed medications on prescribing for people with advanced dementia approaching the end of life. 
522 The authors would like to thank all research participants, GPs, Join Dementia Research, and

523 the Alzheimer's Society, Northern Ireland, who facilitated and supported this study.

524

\section{Conflicts of interest}

526 The authors have no conflicts of interest to declare.

527

528 Funding

529 This research was funded by the Department of Education and Learning (DEL), Northern 530 Ireland, as part of a PhD research degree. The funder had no role in the development, 531 analysis of reporting of the present study.

532

533 Availability of data and materials

534 The audiotaped interviews were deleted from the digital recorder following transcription, in

535 accordance with institutional data protection protocols. Transcripts are not available 536 because this would render participants identifiable.

537

\section{References}

539 1. American Psychiatric Association (2013) Diagnostic and statistical manual of mental disorders. 5th

540 Edition. Arlington, VA: American Psychiatric Publishing

541 2. National Institute for Health and Care Excellence (2017) Dementia: supporting people with

542 dementia and their carers in health and social care. NICE clinical guideline 42. [Online] London: NICE.

543 Available at: https://www.nice.org.uk/guidance/cg42?unlid=9429054072016126125418 [Accessed

544 on 3rd January 2018]

545 3. Liu KPY, Chan CCH, Chu MML, et al. Activities of daily living performance in dementia. Acta Neurol 546 Scand 2007; 116: 91-95.

547 4. Sikkes SAM, De Lange-De Klerk ES, Pijnenburg YA, et al. A systematic review of Instrumental 548 Activities of Daily Living scales in dementia: room for improvement. J Neurol Neurosurg Psychiatry 549 2009; 80: 7-12. 
550 5. Sikkes SAM, Pijnenburg YA, Knol DL, et al. Assessment of instrumental activities of daily living in 551 dementia: diagnostic value of the Amsterdam Instrumental Activities of Daily Living Questionnaire. J 552 Geriatr Psychiatry Neurol 2013; 26: 244-250.

553 6. Mitchell S, Teno J, Kiely D, et al. The clinical course of advanced dementia. N Eng/ J Med 2009; 361 : $554 \quad 1529-1538$.

555 7. Marshall G, Amariglio R, Sperling R, et al. Activities of daily living: where do they fit in the 556 diagnosis of Alzheimer's disease? Neurodegener Dis Manag 2012; 2: 483-491.

557 8. Giebel $C M$, Sutcliffe $C$, Stolt $M$, et al. Deterioration of basic activities of daily living and their 558 impact on quality of life across different cognitive stages of dementia: a European study. Int 559 Psychogeriatr 2014; 26: 1283-1293.

560 9. Reisberg B. Functional Assessment Staging (FAST). Psychopharmacol Bull 1998; 24: 653-659.

561 10. Francis LP. Decision making at the end of life: patients with Alzheimer's or other dementias. 562 Georgia Law Review 2001; 35: 539-592.

563 11. Sampson EL, Thuné-Boyle I, Kukkastenvehmas R, et al. Palliative care in advanced dementia; a 564 mixed methods approach for the development of a complex intervention. BMC Palliat Care 2008; $565 \quad 7: 8$.

566 12. Givens JL, Kiely DK, Carey K, et al. Clinical investigations. Healthcare proxies of nursing home 567 residents with advanced dementia: decisions they confront and their satisfaction with decision568 making. J Am Geriatr Soc 2009; 57: 1149-1155.

569 13. Livingston G, Leavey G, Manela M, et al. Making decisions for people with dementia who lack 570 capacity : qualitative study of family carers in UK. BMJ 2010; 341: c4184.

571 14. Jones L, Harrington J, Scott S, et al. CoMPASs: IOn programme (Care Of Memory Problems in 572 Advanced Stages of dementia: Improving Our Knowledge): protocol for a mixed methods study. BMJ 573 Open 2012; 2: e002265.

574 15. Prorok JC, Horgan S, Seitz DP. Health care experiences of people with dementia and their 575 caregivers: a meta-ethnographic analysis of qualitative studies. Can Med Assoc J 2013; 185: 11955761195. 
577 16. Moreira T, Palladino P. Between truth and hope: on Parkinson's disease, 578 neurotransplantation and the production of the "self". Hist Hum Sci 2005; 18: 55-82.

579 17. Hutchings D, Vanoli A, McKeith I, et al. Good days and bad days: The lived experience 580 and perceived impact of treatment with cholinesterase inhibitors for Alzheimer's disease in 581 the United Kingdom. Dementia 2010; 9: 409-425.

582 18. Geldmacher DS, Frolich L, Doody RS, et al. Realistic expectations for treatment success in 583 Alzheimer's disease. J Nutr Health Aging 2006; 10: 417-429.

584 19. Bell RA, Kravitz RL, Thom D, et al. Unmet expectations for care and the patient-physician 585 relationship. J Gen Intern Med 2002; 17: 817-824.

586 20. Smith A, Kobayashi K, Chappell N, et al. The controversial promises of cholinesterase inhibitors

587 for Alzheimer's disease and related dementias: a qualitative study of caregivers' experiences. J Aging 588 Stud 2011; 25: 397-406.

589 21. Parsons C, McCorry N, Murphy K, et al. Assessment of factors that influence physician decision 590 making regarding medication use in patients with dementia at the end of life. Int J Geriatr Psychiatry $591 \quad 2013 ; 29: 281-290$.

592 22. Deardorff WJ, Feen E, Grossberg GT. The use of cholinesterase inhibitors across all stages of 593 Alzheimer's disease. Drugs Aging 2015; 32: 537-547.

594 23. Reeve E, Bell JS, Hilmer SN. Barriers to optimising prescribing and deprescribing in older adults 595 with dementia: a narrative review. Curr Opin Pharmacol 2015; 10: 168-177.

596 24. Webb S, Lloyd M. Prescribing and referral in general practice: A study of patients' expectations 597 and doctors' actions. Br J Gen Pract 1994; 44: 165-169.

598 25. Cockburn J, Pit S. Prescribing behaviour in clinical practice: patients' expectations and doctors' 599 perceptions of patients' expectations - a questionnaire study. BMJ 1997; 315: 520-523

600 26. Prosser $\mathrm{H}$, Almond S, Walley T. Influences on GPs' decision to prescribe new drugs - the 601 importance of who says what. Fam Pract 2003; 20: 61-68. 
602 27. Post SG, Stuckey JC, Whitehouse PJ, et al. A focus group on cognition-enhancing medications in 603 Alzheimer disease: disparities between professionals and consumers. Alzheimer Dis Assoc Disord 604 2001; 15: 80-88;

605 28. Clare L. Developing awareness about awareness in early-stage dementia: the role of psychosocial 606 factors. Dementia 2002; 1: 295-312.

607 29. Mahoney DF, Cloutterbuck J, Neary S, et al. African American, Chinese, and Latino family 608 caregivers' impressions of the onset and diagnosis of dementia: cross-cultural similarities and 609 differences. Gerontologist 2005; 45: 783-792.

610 30. Hutchings D, Vanoli A, McKeith I, Brothet al. Cholinesterase inhibitors and Alzheimer's disease: 611 patient, carer and professional factors influencing the use of drugs for Alzheimer's disease in the 612 United Kingdom. Dementia 2010a; 9: 427-443.

613 31. Braun V, Clarke V. Using thematic analysis in psychology. Qual Res Psychol 2006; 3: 77-101

614 32. Dicicco-Bloom B, Crabtree BF. The qualitative research interview. Med Educ 2006; 40: 314-321

615 33. Ritchie J, Spencer L. Qualitative data analysis for applied policy research. In BRYMAN, A., \& 616 BURGESS, R.G. Analyzing qualitative data. London: Routledge, 1994.

617 34. Ballard C, Fossey J, Chithramohan R, et al. Quality of care in private sector and NHS facilities for 618 people with dementia: cross sectional survey. BMJ 2001; 323: 426-427

619 35. Sampson EL, Ritchie CW, Lai R, et al. A systematic review of the scientific evidence for the 620 efficacy of a palliative care approach in advanced dementia. Int Psychogeriatr 2005; 17: 31-40.

621 36. Roger KS. A literature review of palliative care, end of life, and dementia. Palliat Support Care 622 2006; 4: 295-303.

623 37. Mitchell SL, Black BS, Ersek M, et al. Advanced dementia: state of the art and priorities for the 624 next decade. Ann Intern Med 2012; 156: 45-51.

625 38. van der Steen JT, Onwuteaka-Philipsen BD, Knol DL, et al. Caregivers' understanding of dementia 626 predicts patients' comfort at death: a prospective observational study. BMC Med 2013; 11: 105.

627 39. Birch D, Draper J. A critical literature review exploring the challenges of delivering effective 628 palliative care to older people with dementia. J Clin Nurs 2008; 17: 1144-1163. 
629 40. Luchins D, Hanrahan P. What is appropriate health care for end-stage dementia? J Am Geriatr 630 Soc 1993; 41: 25-30

631 41. Hanrahan P, Luchins DJ. Access to hospice programs in end-stage dementia: A National Survey of 632 Hospice Programs. J Am Geriatr Soc 1995; 43: 56-59.

633 42. Teno JM, Casey VA, Welch LC, et al. Patientfocused, family-centered end-of-life medical care: 634 views of the guidelines and bereaved family members. J Pain Symptom Manage 2001; 22: 738-751

635 43. van der Steen JT. Dying with dementia: what we know after more than a decade of research. J 636 Alzheimers Dis 2010; 22: 37-55.

637 44. van Nordennen RT, Lavrijsen JC, Heesterbeek MJ, et al. Changes in prescribed drugs between 638 admission and the end of life in patients admitted to palliative care facilities. J Am Med Dir Assoc $6392016 ; 17 ; 514-518$

640 45. Sheehy-Skeffington B, McLean S, Bramwell M. Caregivers experiences of managing medications 641 for palliative care patients at the end of life: qualitative study. Am J Hospice Palliat Med 2014; 31: $642148-154$.

643 46. Holmes HM, Sachs GA, Shega JW, et al. Integrating palliative medicine into the care of persons 644 with advanced dementia: identifying appropriate medication use. J Am Geriatr Soc 2008; 56: 13066451311.

646 47. Parsons C, McCann L, Passmore P, et al. Development and application of medication 647 appropriateness indicators for persons with advanced dementia: a feasibility study. Drugs Aging $648 \quad 2015 ; 32: 67-77$.

649 48. Page AT, Potter K, Clifford R, et al. Medication appropriateness tool for co-morbid health 650 conditions in dementia: consensus recommendations from a multidisciplinary expert panel. Int Med 651 J 2016; 46(10): 1189-1197.

652 49. Toscani F, Di Giulio P, Villani D, et al. Treatments and prescriptions in advanced dementia 653 patients residing in long-term care institutions and at home. J Palliat Med 2013; 16: 31-37.

654 50. Tjia J, Briesacher BA, Peterson D, et al. Use of medications of questionable benefit in advanced 655 dementia. JAMA Intern Med 2014; 174: 1763-1771. 
656 51. Matlow JN, Bronskill SE, Gruneir A, et al. Use of medications of questionable benefit at the end of

657 life in nursing home residents wih advanced dementia. J Am Geriatr Soc 2017; 65: 1535-1542.

658 52. Morin L, Vetrano DL, Grande G, et al. Use of medications of questionable benefit during the last 659 year of life of older adults with dementia. J Am Med Dir Assoc 2017; 18: 551.e1-551.e7.

660 53. Hutchings D, Vanoli A, McKeith, l.et al. Good days and bad days: The lived experience and 661 perceived impact of treatment with cholinesterase inhibitors for Alzheimer's disease in the United 662 Kingdom. Dementia 2010; 9: 409-42

663 54. Doody RS, Geldmacher DS, Gordon B, et al. Open-label, multicenter, phase 3 extension study of 664 the safety and efficacy of donepezil in patients with Alzheimer disease. Arch Neurol 2001; 58: 427665433.

666 55. Daiello L, Ott B, Lapane K, et al. Effect of discontinuing cholinesterase inhibitor therapy on 667 behavioural and mood symptoms in nursing home patients with dementia. Am J Geriatr 668 Pharmacother 2009; 7: 74-83.

669 56. Shega JW, Ellner L, Lau DT, et al. Cholinesterase inhibitor and N-Methyl-D-Aspartic acid receptor 670 antagonist use in older adults with end stage dementia: A survey of hospice medical directors. $J$ 671 Palliat Med 2009; 12:779-783.

672 57. Howard R, McShane R, Lindesay J, et al. Donepezil and memantine for moderate-to-severe 673 Alzheimer's disease. N Engl J Med 2012; 366: 893-903

674 58. Herrmann N, O’Regan J, Ruthirakuhan M, et al. A randomized placebo-controlled discontinuation 675 study of cholinesterase inhibitors in institutionalized patients with moderate to severe Alzheimer 676 disease. J Am Med Dir Assoc 2016; 17: 142-147.

677 59. Lindstrom HA, Smyth KA, Sami SA, et al. Medication use to treat memory loss in dementia: 678 perspectives of persons with dementia and their caregivers. Dementia 2006; 5: 27-50.

679 60. Caron CD, Griffith J, Arcand M. End-of-life decision making in dementia: the perspective of family 680 caregivers. Dementia 2005; 4: 113-136.

681 61. Gillespie R, Mullan J, Harrison L. Managing medications: the role of informal caregivers of older 682 adults and people living with dementia. A review of the literature. J Clin Nurs 2013; 23: 3296-3308. 
683 62. Travis SS, Bethea LS, Winn P. Medication administration hassles reported by family caregivers of 684 dependent elderly persons. J Gerontol A Biol Sci Med Sci 2000; 55: 412-417.

685 63. Smith F, Francis SA, Gray N, et al. A multicentre survey among informal carers who manage 686 medication for older care recipients: problems experienced and development of services. Health Soc 687 Care Community 2003; 11: 138-145

688 64. Francis SA, Smith F, Gray, N, et al. Partnerships between older people and their carers in the 689 management of medication. Int J Older People Nurs 2006; 1: 201-207.

690 65. Muders P, Zahrt-Omar C, Bussmann S, et al. Support for families of patients dying with dementia: 691 a qualitative analysis of bereaved family members' experiences and suggestions. Palliat Support Care 692 2014; 13: 435-442.

693 66. Walace CL. Family communication and decision making at the end of life: a literature review. 694 Palliat Support Care 2015; 13: 815-825.

695 67. Page AT, Clifford RM, Potter K, et al. Exploring the enablers and barriers to implementing the 696 Medication Appropriateness Tool for Comorbid Health conditions during Dementia (MATCH-D) 697 criteria in Australia: a qualitative study. BMJ Open 2017; 7: e017906.

698 68. Reeve E, Low LF, Shakib S, et al. Development and validation of the revised Patients' Attitudes 699 towards Deprescribing (rPATD) questionnaire: versions for older adults and caregivers. Drugs Aging 700 2016; 33: 913-928.

701 69. Gaster B, Larson EB, Curtis JR. Advance directives for dementia: meeting a unique challenge. J 702 Am Med Assoc 2017; 318 (22): 2175-2176.

703 70. Palagyi A, Keay L, Harper J, et al. Barricades and brickwalls: a qualitative study exploring 704 perceptions of medication use and deprescribing in long-term care. BMC Geriatr 2016; 16: 15.

705 71. Marshall MN. Sampling for qualitative research. Fam Pract 1996; 13: 522-525.

706 72. Atkinson R, Flint J. Accessing hidden and hard-to-reach populations: snowball research 707 strategies. Social Research Update: No. 33. Guilford, UK: University of Surrey, Department of 708 Sociology, 2001 


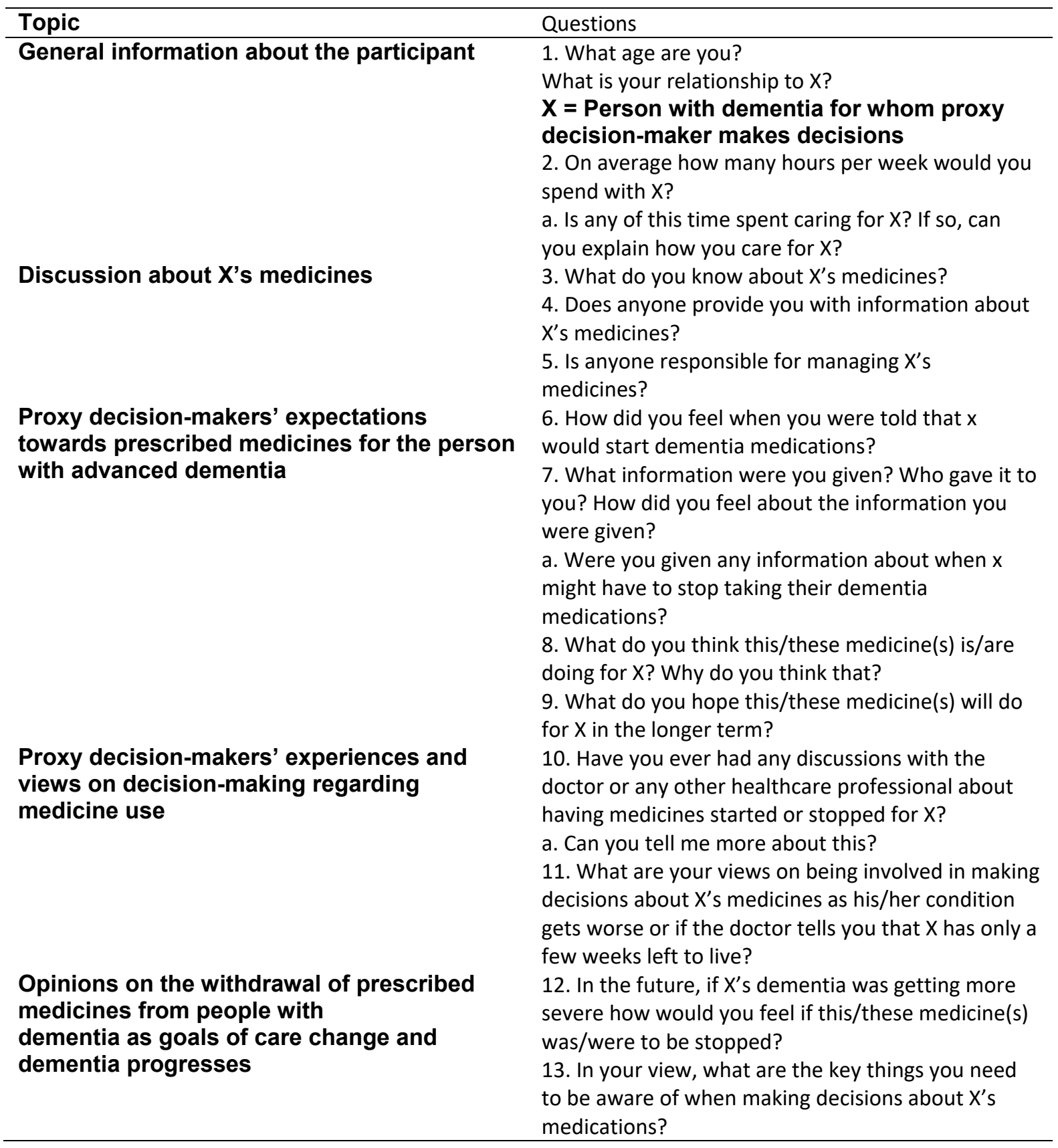


Table 2. Demographic characteristics of participants $(\mathrm{N}=15)$

\section{Demographic characteristic}

Mean age (years) \pm SD of proxy decision-maker

$71 \pm 13.1$

Gender of proxy decision-maker

Female

$10(66.7 \%)$

Male

$5(33.3 \%)$

Mean age (years) \pm SD of person with advanced dementia

$78.8 \pm 9.2$

Relationship of proxy decision-maker to person with advanced dementia

Spouse

$8(53.3 \%)$

Sibling

$2(13.3 \%)$

Child

$4(26.7 \%)$

Grandchild

$1(6.7 \%)$

Place of care

Patient's own home

$7(46.7 \%)$

Nursing home

Proxy decision-maker's home

$3(20.0 \%)$

$\mathrm{SD}=$ Standard deviation 